\title{
Age-adjusted high-sensitivity troponin T cut-off value for risk stratification of pulmonary embolism
}

\author{
Anja Kaeberich ${ }^{1}$, Valerie Seeber ${ }^{1}$, David Jiménez ${ }^{2}$, Maciej Kostrubiec ${ }^{3}$, \\ Claudia Dellas ${ }^{4,5}$, Gerd Hasenfuß ${ }^{4}$, Evangelos Giannitsis ${ }^{6}$, Piotr Pruszczyk ${ }^{3}$, \\ Stavros Konstantinides ${ }^{1}$ and Mareike Lankeit ${ }^{1,4}$
}

\begin{abstract}
Affiliations: ${ }^{1}$ Center for Thrombosis and Hemostasis (CTH), University Medical Center Mainz, Mainz, Germany. ${ }^{2}$ Respiratory Department and Medicine Department, Ramón y Cajal Hospital, Alcalá de Henares University, IRYCIS, Madrid, Spain. ${ }^{3}$ Department of Internal Medicine and Cardiology, Medical University of Warsaw, Warsaw, Poland. "Department of Cardiology and Pulmonology, Heart Center, University of Göttingen, Göttingen, Germany. ${ }^{5}$ Department of Paediatric Cardiology, Heart Center, University of Göttingen, Göttingen, Germany. ${ }^{6}$ Department of Cardiology, Angiology, and Pulmonology, University of Heidelberg, Heidelberg, Germany.
\end{abstract}

Correspondence: Mareike Lankeit, Center for Thrombosis and Hemostasis (CTH), University Medical Center Mainz, Johannes Gutenberg University of Mainz, Langenbeckstraße 1, 55131 Mainz, Germany.

E-mail: mareike.lankeitवunimedizin-mainz.de

ABSTRACT High-sensitivity troponin $\mathrm{T}$ (hsTnT) helps in identifying pulmonary embolism patients at low risk of an adverse outcome. In 682 normotensive pulmonary embolism patients we investigate whether an optimised hsTnT cut-off value and adjustment for age improve the identification of patients at elevated risk.

Overall, 25 (3.7\%) patients had an adverse 30-day outcome. The established hsTnT cut-off value of $14 \mathrm{pg} \cdot \mathrm{mL}^{-1}$ retained its high prognostic value (OR (95\% CI) 16.64 (2.24-123.74); $\left.\mathrm{p}=0.006\right)$ compared with the cut-off value of $33 \mathrm{pg} \cdot \mathrm{mL}^{-1}$ calculated by receiver operating characteristic analysis (7.14 (2.64-19.26); $\mathrm{p}<0.001$ ). In elderly (aged $\geqslant 75$ years) patients, an age-optimised hsTnT cut-off value of $45 \mathrm{pg} \cdot \mathrm{mL}^{-1}$ but not the established cut-off value of $14 \mathrm{pg} \cdot \mathrm{mL}^{-1}$ predicted an adverse outcome. An age-adjusted hsTnT cutoff value $\left(\geqslant 14 \mathrm{pg} \cdot \mathrm{mL}^{-1}\right.$ for patients aged $<75$ years and $\geqslant 45 \mathrm{pg} \cdot \mathrm{mL}^{-1}$ for patients aged $\geqslant 75$ years) provided additive and independent prognostic information on top of the simplified pulmonary embolism severity index (sPESI) and echocardiography (OR 4.56 (1.30-16.01); p=0.018, C-index=0.77). A three-step approach based on the sPESI, hsTnT and echocardiography identified $16.6 \%$ of all patients as being at higher risk (12.4\% adverse outcome).

Risk assessment of normotensive pulmonary embolism patients was improved by the introduction of an age-adjusted hsTnT cut-off value. A three-step approach helped identify patients at higher risk of an adverse outcome who might benefit from advanced therapy.

@ERSpublications

Age-adjusted hsTnT cut-off values for risk stratification of pulmonary embolism provide additive prognostic information. http://ow.ly/FmcZl

This article has supplementary material available from erj.ersjournals.com

Received: Sept 232014 | Accepted after revision: Nov 192014 | First published online: Jan 222015

Support statement: The study was supported by the German Federal Ministry of Education and Research (BMBF 01EO1003). The authors are responsible for the contents of this publication.

Conflict of interest: Disclosures can be found alongside the online version of this article at erj.ersjournals.com

Copyright CERS 2015 


\section{Introduction}

Because of the heterogeneity of patients with acute pulmonary embolism with regard to disease severity and early prognosis, current guidelines [1,2] recommend risk stratification to help physicians in their treatment decisions. Elevation of cardiac troponin ( $\mathrm{T}$ and $\mathrm{I}$ ) plasma concentrations indicates myocardial injury, possibly due to an increased right ventricular afterload, and is associated with an elevated risk of short-term complications and mortality [3,4]. The introduction of high-sensitivity assays facilitated the reliable detection of troponin concentrations below the detection limit of conventional assays [5, 6]. In particular, high-sensitivity troponin $\mathrm{T}$ (hsTnT) levels below $14 \mathrm{pg} \cdot \mathrm{mL}^{-1}$ (defined as the 99th percentile of a healthy reference population with a coefficient of variation of $<10 \%$ ) [5] are useful for the identification of pulmonary embolism patients at low risk $[7,8]$. However, approximately two-thirds of all normotensive patients with acute pulmonary embolism present with hsTnT levels $\geqslant 14 \mathrm{pg} \cdot \mathrm{mL}^{-1}$ on admission resulting in low specificity and positive predictive value of the biomarker [7]. Furthermore, troponin plasma concentrations are known to be affected by several factors, including age, renal function and release kinetics [9-11]. For example, hsTnT levels were considerably higher in patients older than 75 years [12]. At present, it is unknown whether age or the duration of symptoms might affect the prognostic value of hsTnT in acute pulmonary embolism.

In the present study, we investigated whether optimised cut-off values for hsTnT and adjustment for age might provide superior prognostic value for the identification of intermediate-risk pulmonary embolism patients. Furthermore, we tested whether the prognostic value of hsTnT is influenced by the duration of symptoms prior admission.

\section{Material and methods}

Study subjects and study design

The patient population consists of the cohorts of two prospective multicentre studies (derivation [7] and the validation [8] study) investigating the prognostic value of hsTnT in normotensive (systolic blood pressure $>90 \mathrm{mmHg}$ on admission) patients with acute pulmonary embolism. All sites followed the same study protocol (as described in detail in $[7,8]$ and the online supplementary material) allowing for pooling of the patient cohorts. The study protocol was approved by the local ethics committees of all participating sites.

30-day clinical follow-up data were available from all patients included in the study. The primary outcome was an adverse 30-day outcome defined as pulmonary embolism-related death, need for mechanical ventilation, cardiopulmonary resuscitation or catecholamine administration (except for dopamine at an infusion rate of $\leqslant 5 \mu \mathrm{g}$ per $\mathrm{kg}$ of body weight per minute). The secondary outcome was 30 -day all-cause mortality. Causes of death were independently adjudicated by reviewing the medical records and autopsy reports (if performed) by three of the contributing authors (D. Jiménez, M. Kostrubiec and M. Lankeit). Death was determined to be pulmonary embolism-related if it was either confirmed by autopsy, following a clinically severe episode of acute pulmonary embolism and in the absence of an alternative diagnosis.

\section{Laboratory parameters}

Venous plasma samples were collected on admission, immediately stored at $-80^{\circ} \mathrm{C}$, and analysed in batches after a single thaw in the core laboratory of the University of Göttingen (Göttingen, Germany). Cardiac troponin $\mathrm{T}$ concentrations were measured using a highly sensitive quantitative electrochemiluminescence immunoassay (Elecsys 2010; Roche Diagnostics, Mannheim, Germany).

\section{Statistical analysis}

Categorical variables are expressed as absolute number or percentage and were compared using Fisher's exact test or a Chi-squared test, as appropriate. Continuous variables did not follow a normal distribution when tested with the modified Kolmogorov-Smirnov test (Lilliefors test); therefore, these variables are expressed as median with the corresponding interquartile range and were compared using the unpaired Mann-Whitney U-test. Spearman's rank correlation coefficient was used to test for statistical dependence of hsTnT from continuous variables. Receiver operating characteristic (ROC) curve analysis was performed to determine the area under the curve (AUC) of hsTnT with regard to study outcomes. Youden-index quantification was used to identify the optimal hsTnT cut-off values for prediction of the study outcomes. Comparison of the prognostic performances of different hsTnT cut-off values was performed by calculation of sensitivity, specificity, positive predictive value, negative predictive value and the net reclassification improvement (NRI) according to the method described by PENCINA et al.[13]. The prognostic relevance of dichotomous/dichotomised variables with regard to study outcomes was assessed using univariable logistic regression analysis. The results are presented as odds ratios with the corresponding $95 \%$ confidence intervals. To test whether the prognostic value of hsTnT $\geqslant 14 \mathrm{pg} \cdot \mathrm{mL}^{-1}$ with regard to the primary outcome is independent after adjustment for age, renal function and symptom 
onset, these variables were entered into a multivariable model simultaneously. The prognostic relevance of hsTnT cut-off values with regard to study outcomes was estimated using multivariable logistic regression models which also included univariable significant predictors of study endpoints; of note, variables used for calculation of the simplified pulmonary embolism severity index (sPESI) were not included in these models separately. Calculation of Harrell's C-indexes [14] was used to assess the additive prognostic value of hsTnT cut-off values. This approach was also applied for developing the optimal strategy for risk assessment. A two-sided significance level of $\alpha<0.05$ was defined appropriate to indicate statistical significance. Statistical analyses were performed using the SPSS software (version 21.0; SPSS Inc., Chicago, IL, USA) or R (version 2.15.1; The R Foundation for Statistical Computing c/o Institute for Statistics and Mathematics, Wirtschaftsuniversität Wien, Vienna, Austria).

\section{Results}

\section{Baseline findings}

A total of 682 normotensive patients with confirmed acute pulmonary embolism were included in the present study. Of these, 156 (22.9\%) had been included in the derivation [7] and 526 (77.1\%) in the validation [8] study for hsTnT. The clinical baseline characteristics of the study patients are shown in table 1; the diagnostic procedures for confirmation of pulmonary embolism and the treatment performed are described in the online supplementary material. HsTnT plasma concentrations on admission ranged from 0.0001 to $3460 \mathrm{pg} \cdot \mathrm{mL}^{-1}$ with a median level of 21.2 (IQR 7.5-52.8) $\mathrm{pg} \cdot \mathrm{mL}^{-1}$ and correlated with age $(\mathrm{r}=0.317, \mathrm{p}<0.001)$, renal function (glomerular filtration rate; $\mathrm{r}=-0.314, \mathrm{p}<0.001)$ and heart rate $(\mathrm{r}=0.276$, $\mathrm{p}<0.001)$. Overall, $412(60.4 \%)$ patients had hsTnT levels above the established cut-off value of $14 \mathrm{pg} \cdot \mathrm{mL}^{-1}$. As shown in table 1 , patients with hsTnT $\geqslant 14 \mathrm{pg} \cdot \mathrm{mL}^{-1}$ were older, more frequently diagnosed with chronic heart failure, chronic pulmonary disease and renal insufficiency, and presented more often with syncope, tachycardia, right ventricular (RV) dysfunction on echocardiography, and an sPESI [15]) $\geqslant 1$.

\section{Patient cohort-specific hsTnT cut-off values for risk assessment}

During the first 30 days, $25(3.7 \%)$ patients reached the primary outcome (adverse 30-day outcome) and 29 (4.3\%) patients reached the secondary outcome (30-day all-cause mortality). A total of 10 deaths were

TABLE 1 Baseline characteristics, medical history, and initial presentation of 682 normotensive patients with acute pulmonary embolism

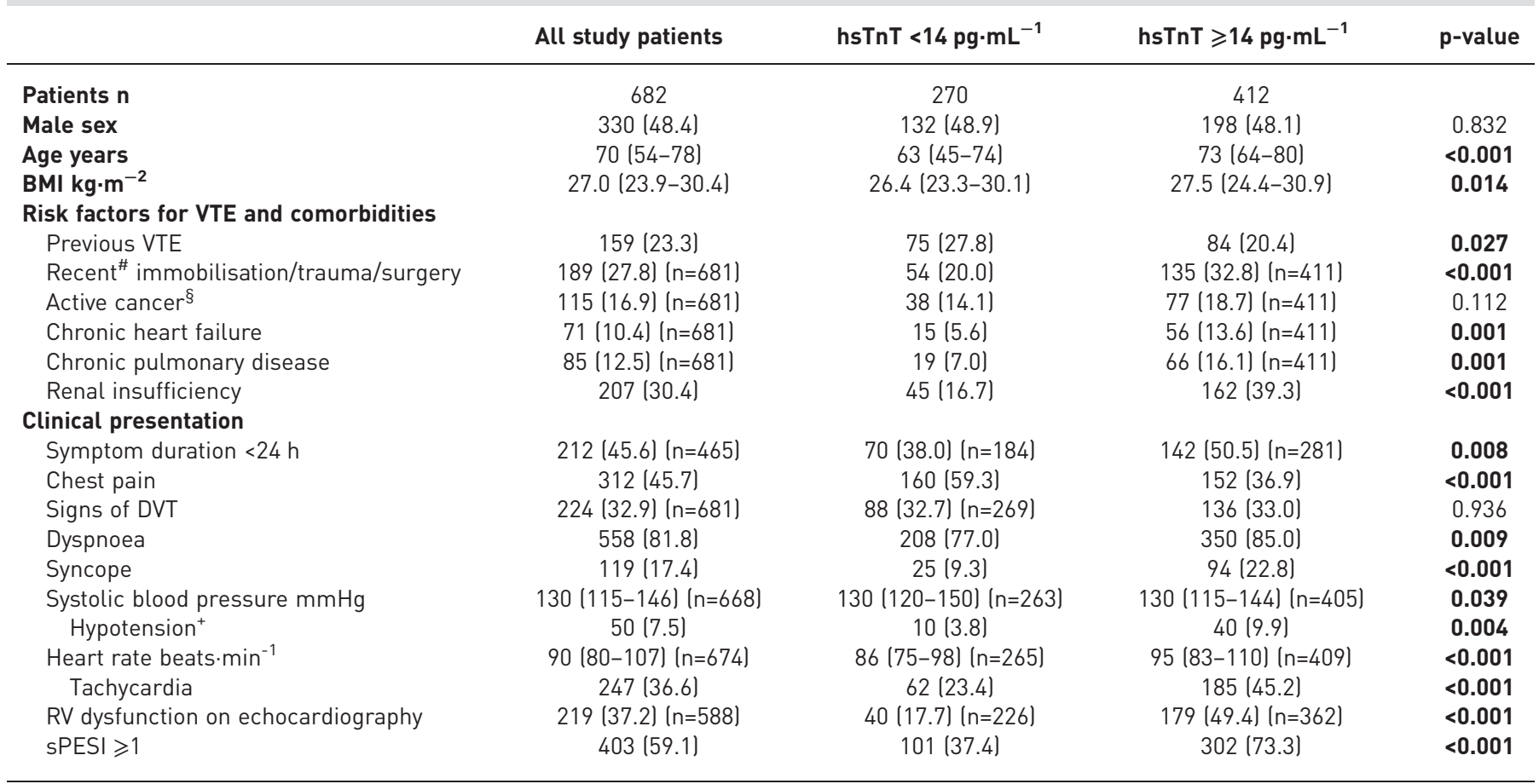

Data are presented as $\mathrm{n}(\%)$ or median (interquartile range), unless otherwise stated. Patients were stratified according the high-sensitivity troponin T (hsTnT) cut-off value of $14 \mathrm{pg} \cdot \mathrm{mL}^{-1}$. BMI: body mass index; VTE: venous thromboembolism; DVT: deep vein thrombosis; RV: right ventricular; sPESI: simplified pulmonary embolism severity index. ${ }^{\#}$ : within the previous 4 weeks; ${ }^{\S}$ : defined as active malignancy, anti-tumour therapy within the last 6 months, or metastatic state; ${ }^{+}$: defined as systolic blood pressure between 90 and $100 \mathrm{mmHg}$ on admission. 
directly related to pulmonary embolism (34.5\% of all deaths; $1.5 \%$ pulmonary embolism-related mortality rate); additionally, five patients died of recurrent pulmonary embolism, two of major fatal bleeding, five of cancer, three of chronic heart failure, three of chronic pulmonary disease and one patient each of hepatic failure and sepsis, respectively. As expected, patients who reached either the primary or the secondary outcome had significantly higher median levels of hsTnT on admission compared with patients with a favourable 30-day clinical course (primary outcome: 56.4 (33.4-100.1) versus $19.2(7.3-50.1) \mathrm{pg} \cdot \mathrm{mL}^{-1}$, $\mathrm{p}<0.001$; secondary outcome: 52.1 (22.1-93.9) versus $\left.19.3(7.3-50.4) \mathrm{pg} \cdot \mathrm{mL}^{-1}, \mathrm{p}=0.002\right)$. ROC analysis confirmed that hsTnT was an indicator of the primary and secondary outcome in normotensive patients with acute pulmonary embolism (fig. 1). The prognostic value of hsTnT with regard to symptom duration prior admission is described in the online supplementary material. HsTnT concentrations of 33 and $42 \mathrm{pg} \cdot \mathrm{mL}^{-1}$ were identified as optimal cut-off values for predicting an adverse 30 -day outcome and 30-day all-cause mortality, respectively. However, using univariable logistic regression analysis, the established cut-off value of $14 \mathrm{pg} \cdot \mathrm{mL}^{-1}$ was associated with a higher odds ratio (OR 16.64, 95\% CI 2.24-123.74; $\mathrm{p}=0.006)$ for an adverse 30 -day outcome compared with the cohort-specific cut-off value of $33 \mathrm{pg} \cdot \mathrm{mL}^{-1}$ (OR 7.14, 95\% CI 2.64-19.26, $\mathrm{p}<0.001$; table 2). This was also confirmed by the lack of improvement in prognostic information by the use of the cohort-specific cut-off value, as indicated by the NRI (table 2). As shown in table 3, besides hsTnT, tachycardia, hypotension (systolic blood pressure between 90 and $100 \mathrm{mmHg}$ on admission), hypoxia (oxyhaemoglobin saturation $<90 \%$ ), chronic cardiopulmonary disease, RV dysfunction on echocardiography and a sPESI $\geqslant 1$ were also identified as univariable predictors of an adverse 30-day outcome.

\section{Age-adjusted hsTnT cut-off values improve risk stratification}

Median hsTnT levels were higher in patients aged $\geqslant 75$ years of age $(n=248)$ compared with younger $(<75$ years; $\mathrm{n}=434)$ patients $\left(30.53(13.72-67.51)\right.$ versus $15.24(4.90-41.74) \mathrm{pg} \cdot \mathrm{mL}^{-1}$, respectively; $\left.\mathrm{p}<0.001\right)$. In a multivariable logistic regression analysis, the predictive value of $\mathrm{hsTnT} \geqslant 14 \mathrm{pg} \cdot \mathrm{mL}^{-1}$ remained significant after adjustment for age, renal insufficiency and symptom duration (OR 14.26, 95\% CI 1.87108.53; $\mathrm{p}=0.010)$. By ROC analysis, an optimised hsTnT cut-off value of $12 \mathrm{pg} \cdot \mathrm{mL}^{-1}$ for patients aged $<75$ years (AUC $0.76,95 \%$ CI $0.66-0.85 ; \mathrm{p}=0.002$ ), and of $45 \mathrm{pg} \cdot \mathrm{mL}^{-1}$ for elderly patients (AUC $0.74,95 \%$ CI $0.64-0.84 ; \mathrm{p}=0.005)$ were calculated for prediction of an adverse 30-day outcome. Reclassification of elderly patients using the age-optimised cut-off value of $45 \mathrm{pg} \cdot \mathrm{mL}^{-1}$ provided better risk prediction compared with the established hsTnT cut-off value of $14 \mathrm{pg} \cdot \mathrm{mL}^{-1}$ (NRI $0.18,95 \%$ CI $0.01-0.36 ; \mathrm{p}=0.041$ ) (table 2). Alternatively, in patients aged $<75$ years, the age-optimised hsTnT cut-off of $12 \mathrm{pg} \cdot \mathrm{mL}^{-1} \mathrm{did}$ not improve prediction of an adverse 30-day outcome compared with the established hsTnT cut-off value of $14 \mathrm{pg} \cdot \mathrm{mL}^{-1}$ (NRI 0.01, 95\% CI $-0.07-0.09 ; \mathrm{p}=0.873$ ).

An age-adjusted hsTnT cut-off value $\left(\geqslant 14 \mathrm{pg} \cdot \mathrm{mL}^{-1}\right.$ in patients aged $<75$ years and $\geqslant 45 \mathrm{pg} \cdot \mathrm{mL}^{-1}$ in patients aged $\geqslant 75$ years) was associated with an 8.7 -fold increased risk for the primary study outcome (OR 8.67, 95\% CI 2.57-29.26; $\mathrm{p}<0.001)$. Importantly, entering the age-adjusted hsTnT cut-off value into a
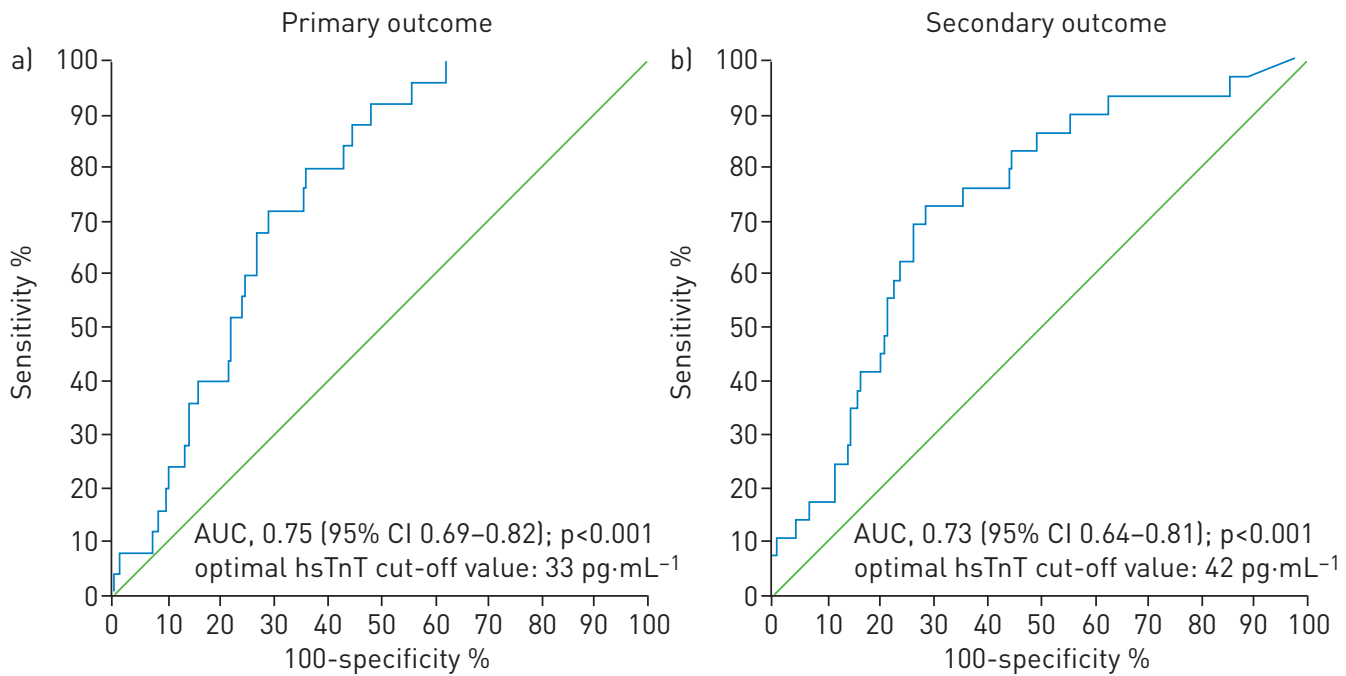

FIGURE 1 Receiver operating characteristics curves for high-sensitivity troponin $\mathrm{T}$ (hsTnT) levels on admission with regard to the a) primary (adverse 30-day outcome) and b) secondary (30-day all-cause mortality) outcome in normotensive pulmonary embolism. AUC: area under the curve. 
TABLE 2 Prognostic performance of different high-sensitivity troponin T (hsTnT) cut-off values in all study patients and in elderly (aged $\geqslant 75$ years) patients with regard to an adverse 30 -day outcome

\begin{tabular}{|c|c|c|c|c|c|c|}
\hline & Sensitivity & Specificity & PPV & NPV & $\begin{array}{l}\text { NRI (95\% CI), } \\
\text { p-value }\end{array}$ & $\begin{array}{l}\text { OR (95\% CI), } \\
\text { p-value }\end{array}$ \\
\hline \multicolumn{7}{|l|}{ All study patients $(n=682)$} \\
\hline $\begin{array}{l}\text { hs } T n T \geqslant 33 \mathrm{pg} \cdot \mathrm{mL}^{-1} \\
\quad \text { (patient cohort-specific) }\end{array}$ & $80(61-91)$ & $64(60-67)$ & $8(5-12)$ & $99(97-100)$ & $\begin{array}{c}0.07(-0.09-0.23) \\
p=0.385\end{array}$ & $\begin{array}{c}7.14(2.64-19.26) \\
\mathbf{p}<0.001\end{array}$ \\
\hline Age-adjusted hsTnT cut-off value ${ }^{\#}$ & $88(70-96)$ & $54(50-58)$ & $7(5-10)$ & $99(98-100)$ & $\begin{array}{c}0.05(-0.06-0.17) \\
p=0.369\end{array}$ & $\begin{array}{c}8.67(2.57-29.26) \\
\mathbf{p}<0.001\end{array}$ \\
\hline \multicolumn{7}{|l|}{ Age $\geqslant 75$ years $(n=248)$} \\
\hline $\mathrm{hsTnT} \geqslant 14 \mathrm{pg} \cdot \mathrm{mL}^{-1}$ (established) & $100(76-100)$ & $28(22-34)$ & $7(4-11)$ & $100(94-100)$ & & ก \\
\hline hsTnT $\geqslant 45 \mathrm{pg} \cdot \mathrm{mL}^{-1}$ (age-optimised) & $83(55-95)$ & $64(58-70)$ & $11(6-19)$ & $99(95-100)$ & $\begin{array}{c}0.18(0.01-0.36) \\
\quad p=0.041\end{array}$ & $\begin{array}{c}9.05(1.94-42.26) \\
p=0.005\end{array}$ \\
\hline
\end{tabular}

Data are presented as $\%(95 \% \mathrm{Cl})$, unless otherwise stated. Abbreviations: PPV: positive predictive value; NPV: negative predictive value; NRI: net reclassification improvement; $\mathrm{Cl}$ : confidence interval; OR: odds ratio; hsTnT: high-sensitivity troponin T. \#: the age-adjusted hsTnT cut-off value was defined as hsTnT levels $\geqslant 14 \mathrm{pg} \mathrm{mL}^{-1}$ in young ( $<75$ years) patients and hsTnT levels $\geqslant 45 \mathrm{pg} \mathrm{mL}^{-1}$ in elderly ( $\geqslant 75$ years) patients. १: calculation of the odds ratio was not possible since all patients with hsTnT $<14 \mathrm{pg} \mathrm{mL}^{-1}$ had a favourable outcome (sensitivity $100 \%$ ).

multivariable model with the sPESI and evidence of RV dysfunction on echocardiography, hsTnT provided independent and additive prognostic information (OR 4.56, 95\% CI 1.30-16.01; p=0.018, $\mathrm{C}$-index $=0.77$ ), on top of the two other variables (C-index $=0.67$; table 3$)$. In contrast, inclusion of the hsTnT cut-off value of $14 \mathrm{pg} \cdot \mathrm{mL}^{-1}$ (regardless of the patient's age) into the same multivariable model did not provide independent prognostic information (OR 7.11, 95\% CI 0.91-55.43; p=0.061) (table 3). The age-adjusted hsTnT cut-off value also provided independent and additive prognostic information for identification of patients with an increased risk of 30-day all-cause mortality (OR 3.38, 95\% CI 1.33-8.58; $\mathrm{p}=0.010$, C-index $=0.74$ ) (table $1 \mathrm{~s}$ of the online supplementary material).

Optimising risk assessment using a three-step approach

Seeking to optimise the risk assessment strategy for normotensive patients with pulmonary embolism, we tested a three-step algorithm (fig. 2). Of 279 (40.9\%) patients classified as "low-risk" (sPESI 0), two (0.7\%) patients had an adverse 30-day outcome as opposed to 23 (5.7\%) of 403 patients classified as high-risk (sPESI $\geqslant 1$; fig. 2). As shown in table 4 , addition of hsTnT to the sPESI provided additive prognostic information (OR 6.59, 95\% CI 1.93-22.44; $\mathrm{p}=0.003$, specificity 68\%, C-index 0.77 ) compared with a sPESI

TABLE 3 Predictors of adverse 30-day outcome in normotensive pulmonary embolism

\begin{tabular}{|c|c|c|c|c|}
\hline & OR & $95 \% \mathrm{Cl}$ & p-value & C-index \\
\hline \multicolumn{5}{|l|}{ Univariable logistic regression analysis } \\
\hline Chronic cardiopulmonary disease & 3.04 & $1.33-6.93$ & 0.008 & \\
\hline Tachycardia & 2.70 & $1.19-6.10$ & 0.017 & \\
\hline Hypotension & 3.32 & $1.19-9.27$ & 0.022 & \\
\hline Hypoxia & 3.65 & $1.51-8.81$ & 0.004 & \\
\hline RV dysfunction on echocardiography & 4.08 & $1.65-10.07$ & 0.002 & \\
\hline SPESI $\geqslant 1$ & 8.38 & $1.96-35.85$ & 0.004 & \\
\hline \multicolumn{5}{|l|}{ Multivariable logistic regression analysis } \\
\hline SPESI $\geqslant 1$ & 6.18 & $1.42-26.92$ & 0.015 & 0.67 \\
\hline RV dysfunction on echocardiography & 3.23 & $1.29-8.07$ & 0.012 & \\
\hline \multicolumn{5}{|l|}{ Additional impact } \\
\hline $\mathrm{hs} T \mathrm{nT} \geqslant 14 \mathrm{pg} \cdot \mathrm{mL}^{-1}$ & 7.11 & $0.91-55.43$ & 0.061 & 0.76 \\
\hline Age-adjusted hsTnT cut-off value ${ }^{\#}$ & 4.56 & $1.30-16.01$ & 0.018 & 0.77 \\
\hline
\end{tabular}




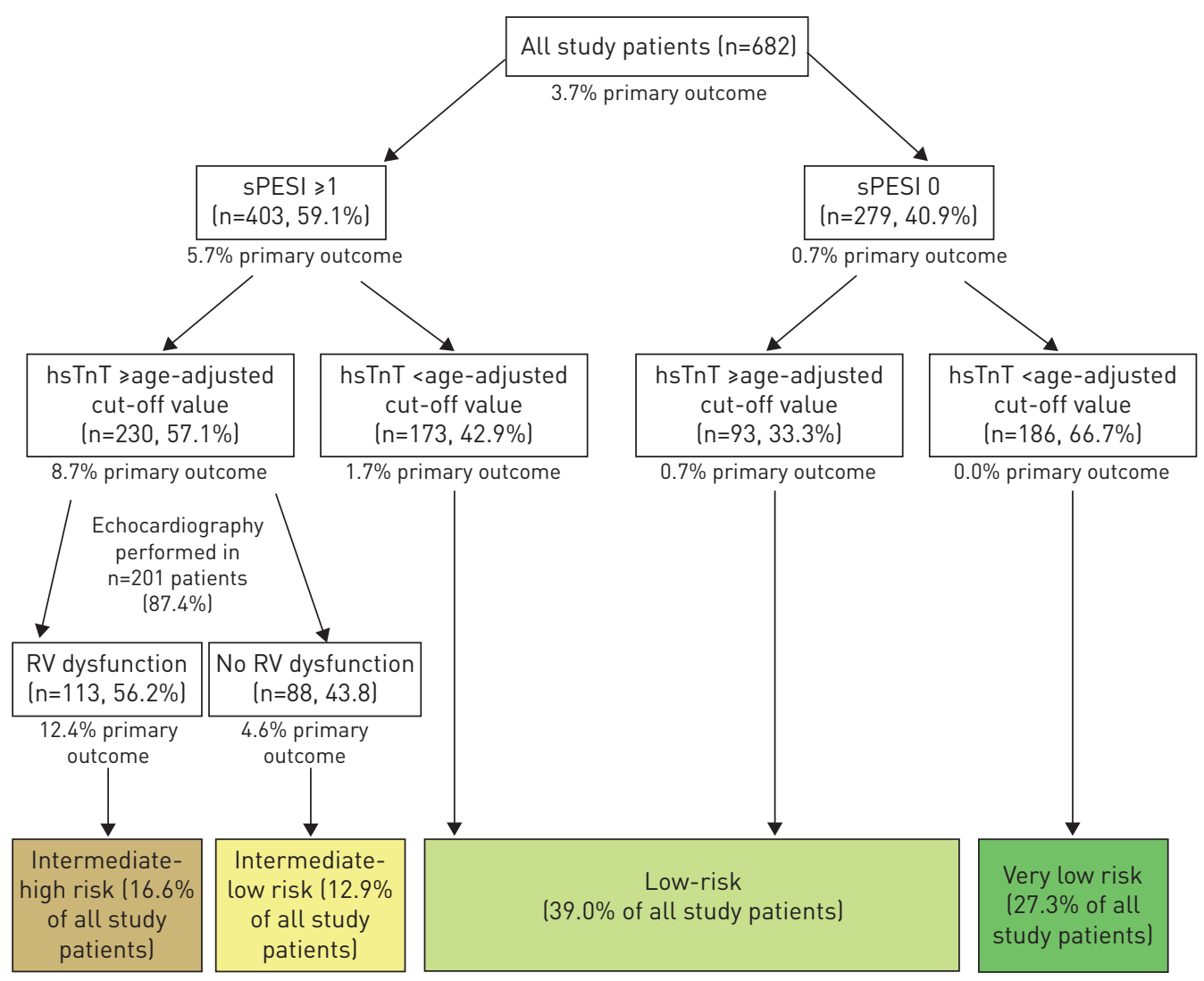

FIGURE 2 Stepwise approach for risk assessment based on the simplified pulmonary embolism severity index (sPESI), an age-adjusted high-sensitivity troponin $\mathrm{T}$ (hsTnT) cut-off value, and echocardiographic evidence of right ventricular (RV) dysfunction. The age-adjusted hsTnT cut-off value was defined as hsTnT levels $\geqslant 14 \mathrm{pg} \cdot \mathrm{mL}^{-1}$ in young (age $<75$ years) patients and hsTnT levels $\geqslant 45 \mathrm{pg} \cdot \mathrm{mL}^{-1}$ in elderly ( $\geqslant 75$ years) patients.

$\geqslant 1$ alone (specificity 42\%, C-index 0.67 ). The number of patients at risk could be reduced from 403 to 230 (33.7\% of the total study population and $57.1 \%$ of the patients with sPESI $\geqslant 1$ ); of those, 2 patients $(8.7 \%)$ reached the primary outcome (fig. 2, left side). Of note, both patients with a sPESI of 0 and an adverse 30-day outcome (both required catecholamine administration due to hemodynamic collapse) were correctly reclassified by the age-adjusted hsTnT cut-off value (fig. 2).

In order to identify a subgroup of normotensive patients at even higher risk (who might benefit from recanalisation therapy, as suggested by the results of a recent trial [16]), we added RV dysfunction on echocardiography to the algorithm as the third step. Of note, addition of RV dysfunction on echocardiography to the multivariable model did not provide independent prognostic information in the total study population or in the subgroup of patients with a sPESI $\geqslant 1$ (table 4). However, including RV dysfunction on echocardiography as a third step in the risk assessment algorithm helped identify a subgroup of patients (16.6\% of the total study population) as being at "intermediate-high risk" (12.4\% adverse 30-day outcome; fig. 2) with a specificity of $84 \%$ (table 4 ).

\section{Discussion}

Prognostic value of hsTnT in patients with pulmonary embolism

Thresholds for biomarkers should be selected according to the intended clinical application. While reference values defining "normal" biomarker concentrations (such as the 99th percentile of a healthy reference population with a coefficient of variation of $<10 \%$ ) are especially useful for diagnostic purposes due to their usually high negative predictive value, thresholds may need to be adapted for prognostic use in order to reduce the number of false positive tests. For instance, while a normal $N$-terminal pro-brain natriuretic peptide level $<125 \mathrm{pg} \cdot \mathrm{mL}^{-1}$ virtually excludes the presence of significant heart failure [17], the prognostically relevant cut-off value in normotensive patients with pulmonary embolism is as high as $600 \mathrm{pg} \cdot \mathrm{mL}^{-1}[18]$.

The prognostic relevance of cardiac troponins for risk stratification of normotensive pulmonary embolism has continued to evolve during the past decade. Elevated troponin levels serve as predictors of an adverse 
TABLE 4 Development of a stepwise approach for risk assessment (primary outcome)

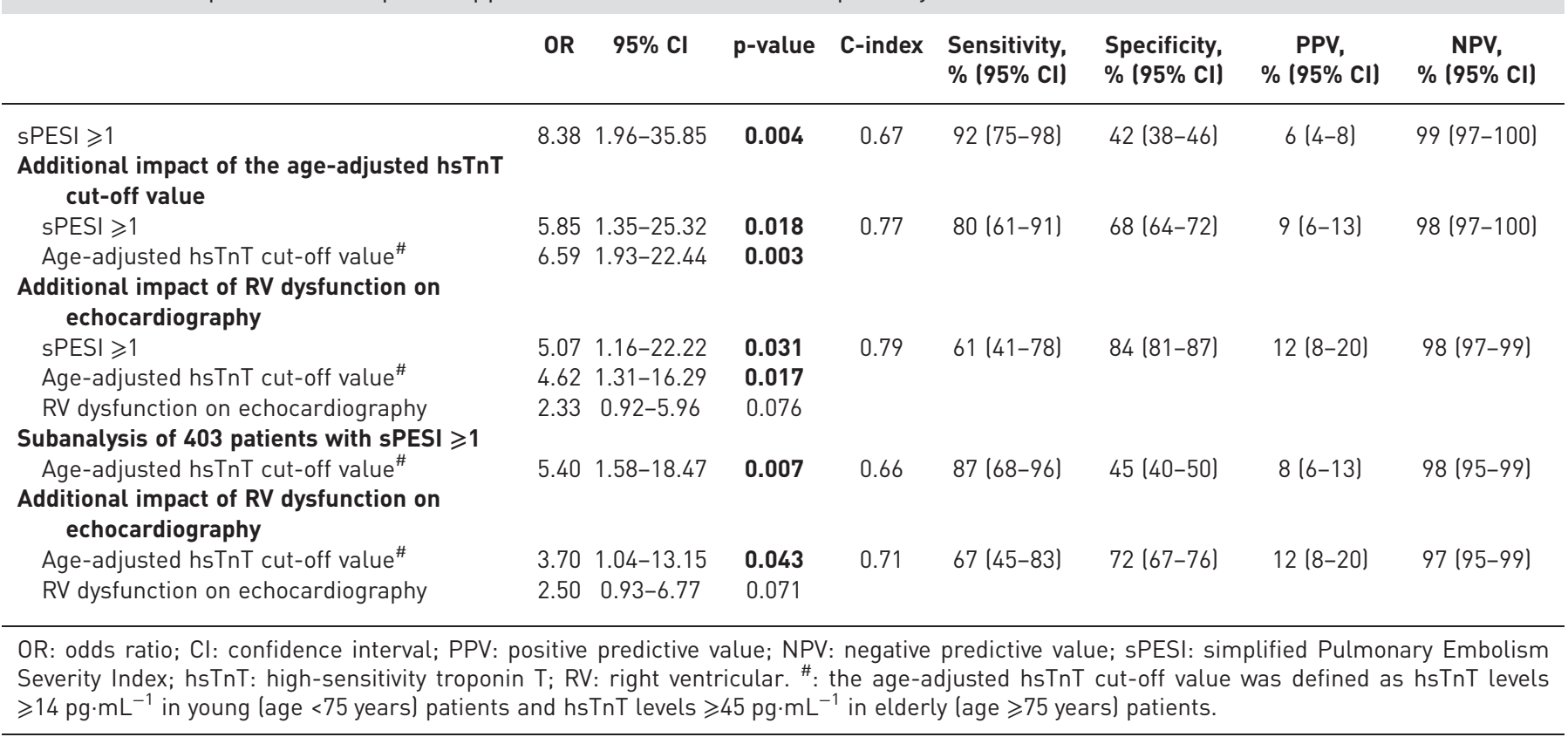

short-term course [3], while plasma concentrations below the threshold of high-sensitivity assays (e.g. $14 \mathrm{pg} \cdot \mathrm{mL}^{-1}$ for hsTnT) are especially useful for identification of low-risk patients with a favourable prognosis $[5,19,20]$. The potential therapeutic consequences of elevated troponin plasma concentrations have recently been demonstrated in the Pulmonary Embolism Thrombolysis (PEITHO) study [16]. In that study, patients with intermediate-risk pulmonary embolism, defined by RV dysfunction on echocardiography or computed tomography plus a positive troponin test, were randomised in a double-blind manner to treatment with tenecteplase or placebo (plus anticoagulation in both arms). Of patients who received the thrombolytic agent, $2.6 \%$ reached the primary endpoint (death or haemodynamic decompensation within 7 days) compared with $5.6 \%$ of those randomised to placebo; this effect corresponded to a relative risk reduction of $56 \%$ (OR $0.44,95 \%$ CI $0.23-0.87$; $=0.02$ ). However, thresholds for a positive troponin test were not prospectively defined in that study and different assays (including high-sensitivity assays) were used by the participating sites. In the present multicentre study of 682 normotensive patients with acute pulmonary embolism, we could demonstrate that the previously validated and established cut-off value of $14 \mathrm{pg} \cdot \mathrm{mL}^{-1}$ [8] retained its superior prognostic value compared with the "optimal" cut-off value of $33 \mathrm{pg} \cdot \mathrm{mL}^{-1}$ calculated by ROC analysis in the present patient population.

\section{Additive prognostic information by using an age-adjusted hsTnT cut-off value}

The use of age-adjusted biomarker cut-off values has recently attracted interest in acute pulmonary embolism, as several studies showed an improved diagnostic performance of age-adjusted D-dimer thresholds [21]. In addition, elderly patients with acute pulmonary embolism are considered to have a higher risk of an adverse early outcome, highlighting the importance of reliable risk stratification tools in this patient subgroup: in the PEITHO trial [16], patients aged $\geqslant 75$ years more frequently reached the primary endpoint $(4.3 \%$ in the tenecteplase arm and $6.7 \%$ in the placebo arm) compared with patients aged $<75$ years $(1.7 \%$ and $5.1 \%$, respectively). By comparison, in the present cohort study, $4.8 \%$ of the patients aged $\geqslant 75$ years had an adverse 30 -day outcome compared with $3.0 \%$ of the patients aged $<75$ years. An age-adjusted hsTnT cut-off value provided improved prognostic value compared with the established hsTnT cut-off value of $14 \mathrm{pg} \cdot \mathrm{mL}^{-1}$ for the prediction of an adverse 30 -day outcome in elderly patients (table 2).

Advanced age has been shown to influence the diagnostic and prognostic value of cardiac troponins in cardiovascular disease such as acute coronary syndrome $[9,12]$. In the present multicentre cohort study, we could show that the use of an age-adjusted hsTnT cut-off value $\left(14 \mathrm{pg} \cdot \mathrm{mL}^{-1}\right.$ in patients aged $<75$ years and $45 \mathrm{pg} \cdot \mathrm{mL}^{-1}$ in patients aged $\geqslant 75$ years) exhibited a good prognostic performance. Importantly, the prognostic information provided by the age-adjusted hsTnT cut-off value was independent and additive (OR 4.62, 95\% CI 1.31-16.29; $\mathrm{p}=0.017$, C-index 0.77) to that of the sPESI and echocardiography (C-index 0.67; table 3). The calculated optimal hsTnT cut-off value of $45 \mathrm{pg} \cdot \mathrm{mL}^{-1}$ for pulmonary embolism patients 
aged $\geqslant 75$ years is in agreement with the hsTnT thresholds reported for elderly patients with other cardiovascular diseases $[9,22]$, such as acute myocardial infarction.

\section{A three-step approach for risk assessment of normotensive pulmonary embolism}

In order to further optimise the risk assessment strategy for normotensive patients with pulmonary embolism, we developed a three-step algorithm (fig. 2) based on the sPESI, the age-adjusted hsTnT cut-off value and echocardiographic evidence of RV dysfunction. Using this three-step approach, we were able to identify $16.6 \%$ of all patients as being at intermediate-high risk with $12.4 \%$ of them reaching the primary outcome. While echocardiographic evidence of RV dysfunction was helpful for further stratifying patients with a sPESI $\geqslant 1$ and hsTnT above the age-adjusted cut-off value in an "intermediate-high" and an "intermediate-low" risk group, echocardiographic examination may not be necessary in patients with a sPESI of 0 or hsTnT below the age-adjusted cut-off value. This three-step approach supports the findings of Bova et al. [23] suggesting a multidimensional seven-point risk index based on (mild) hypotension, tachycardia, RV dysfunction on echocardiography and elevated cardiac troponin for identification of intermediate-risk pulmonary embolism. In the present patient cohort, a one-point increase in the "Bova score" using the age-adjusted hsTnT cut-off value was associated with a 1.69 -fold increased risk of an adverse 30-day outcome (95\% CI 1.34-2.12; $<<0.001)$.

\section{Conclusions}

In elderly (age $\geqslant 75$ years) patients with acute pulmonary embolism, an age-optimised hsTnT cut-off value of $45 \mathrm{pg} \cdot \mathrm{mL}^{-1}$ is superior to the established cut-off value of $14 \mathrm{pg} \cdot \mathrm{mL}^{-1}$ in predicting an adverse 30 -day outcome. The use of an age-adjusted hsTnT cut-off value $\left(\geqslant 14 \mathrm{pg} \mathrm{mL}^{-1}\right.$ for patients aged $<75$ years and $\geqslant 45 \mathrm{pg} \cdot \mathrm{mL}^{-1}$ for patients aged $\geqslant 75$ years) provided prognostic information which was additive to that of clinical and echocardiographic findings. A three-step approach based on the sPESI, an age-adjusted hsTnT cut-off value and echocardiographic evidence of RV dysfunction, might help identify patients with a higher risk of an adverse 30-day outcome who require monitoring and, possibly, early reperfusion therapy. However, for defining the optimal treatment strategy of intermediate-high risk pulmonary embolism patients, further criteria such as the individual bleeding risk should be taken into consideration.

\section{References}

1 Konstantinides SV, Torbicki A, Agnelli G, et al. ESC Guidelines on the diagnosis and management of acute pulmonary embolism: The Task Force for the Diagnosis and Management of Acute Pulmonary Embolism of the European Society of Cardiology (ESC). Endorsed by the European Respiratory Society (ERS). Eur Heart J 2014; 35: 3033-3073.

2 Jaff MR, McMurtry MS, Archer SL, et al. Management of massive and submassive pulmonary embolism, iliofemoral deep vein thrombosis, and chronic thromboembolic pulmonary hypertension: a scientific statement from the American Heart Association. Circulation 2011; 123: 1788-1830.

3 Becattini C, Vedovati MC, Agnelli G. Prognostic value of troponins in acute pulmonary embolism: a meta-analysis. Circulation 2007; 116: 427-433.

4 Jiménez $\mathrm{D}$, Uresandi $\mathrm{F}$, Otero $\mathrm{R}$, et al. Troponin-based risk stratification of patients with acute nonmassive pulmonary embolism: systematic review and metaanalysis. Chest 2009; 136: 974-982.

5 Giannitsis E, Kurz K, Hallermayer K, et al. Analytical validation of a high-sensitivity cardiac troponin $\mathrm{T}$ assay. Clin Chem 2010; 56: 254-261.

6 Haaf $\mathrm{P}$, Reichlin $\mathrm{T}$, Twerenbold $\mathrm{R}$, et al. Risk stratification in patients with acute chest pain using three high-sensitivity cardiac troponin assays. Eur Heart J 2014; 35: 365-375.

7 Lankeit M, Friesen D, Aschoff J, et al. Highly sensitive troponin T assay in normotensive patients with acute pulmonary embolism. Eur Heart J 2010; 31: 1836-1844.

8 Lankeit M, Jiménez D, Kostrubiec M, et al. Predictive value of the high-sensitivity troponin $\mathrm{T}$ assay and the simplified Pulmonary Embolism Severity Index in hemodynamically stable patients with acute pulmonary embolism: a prospective validation study. Circulation 2011; 124: 2716-2724.

9 Normann J, Mueller M, Biener M, et al. Effect of older age on diagnostic and prognostic performance of high-sensitivity troponin T in patients presenting to an emergency department. Am Heart J 2012; 164: 698-705.

10 Khan NA, Hemmelgarn BR, Tonelli M, et al. Prognostic value of troponin T and I among asymptomatic patients with end-stage renal disease: a meta-analysis. Circulation 2005; 112: 3088-3096.

11 Hessel MH, Michielsen EC, Atsma DE, et al. Release kinetics of intact and degraded troponin I and $\mathrm{T}$ after irreversible cell damage. Exp Mol Pathol 2008; 85: 90-95.

12 Eggers KM, Lind L, Venge P, et al. Factors influencing the 99th percentile of cardiac troponin I evaluated in community-dwelling individuals at 70 and 75 years of age. Clin Chem 2013; 59: 1068-1073.

13 Pencina MJ, D'Agostino RB Sr, D'Agostino RB Jr, et al. Evaluating the added predictive ability of a new marker: from area under the ROC curve to reclassification and beyond. Stat Med 2008; 27: 157-172.

14 Harrell FE Jr, Lee KL, Mark DB. Multivariable prognostic models: issues in developing models, evaluating assumptions and adequacy, and measuring and reducing errors. Stat Med 1996; 15: 361-387.

15 Jiménez D, Aujesky D, Moores L, et al. Simplification of the pulmonary embolism severity index for prognostication in patients with acute symptomatic pulmonary embolism. Arch Intern Med 2010; 170: 1383-1389.

16 Meyer G, Vicaut E, Danays T, et al. Fibrinolysis for patients with intermediate-risk pulmonary embolism. $N$ Engl J Med 2014; 370: 1402-1411. 
17 McMurray JJ, Adamopoulos S, Anker SD, et al. ESC Guidelines for the diagnosis and treatment of acute and chronic heart failure 2012: The Task Force for the Diagnosis and Treatment of Acute and Chronic Heart Failure 2012 of the European Society of Cardiology. Developed in collaboration with the Heart Failure Association (HFA) of the ESC. Eur Heart J 2012; 33: 1787-1847.

18 Lankeit M, Jiménez D, Kostrubiec M, et al. Validation of N-terminal pro-brain natriuretic peptide cut-off values for risk stratification of pulmonary embolism. Eur Respir J 2014; 43: 1669-1677.

19 Keller T, Zeller T, Peetz D, et al. Sensitive troponin I assay in early diagnosis of acute myocardial infarction. N Engl J Med 2009; 361: 868-877.

20 Reichlin T, Hochholzer W, Bassetti S, et al. Early diagnosis of myocardial infarction with sensitive cardiac troponin assays. N Engl J Med 2009; 361: 858-867.

21 Righini M, Van Es J, Den Exter PL, et al. Age-adjusted D-dimer cutoff levels to rule out pulmonary embolism: the ADJUST-PE study. JAMA 2014; 311: 1117-1124.

22 Reiter M, Twerenbold R, Reichlin T, et al. Early diagnosis of acute myocardial infarction in patients with pre-existing coronary artery disease using more sensitive cardiac troponin assays. Eur Heart J 2012; 33: 988-997.

23 Bova C, Sanchez O, Prandoni P, et al. Identification of intermediate-risk patients with acute symptomatic pulmonary embolism. Eur Respir J 2014; 44: 694-703. 